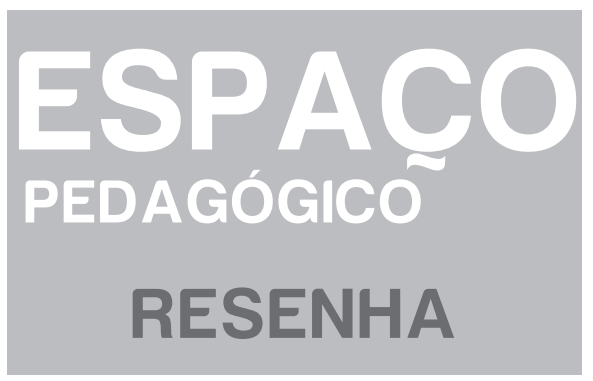





\section{Semiósis e pensamento humano: registros semióticos e aprendizagens intelectuais ${ }^{1}$}

Flávia de Andrade Niemann*

O francês Raymond Duval é psicólogo e filósofo. De 1970 a 1995, trabalhou no Instituto de Pesquisa em Educação Matemática (Irem) de Estrasburgo, na França, onde desenvolveu estudos significativos em psicologia cognitiva, principalmente relacionados ao funcionamento cognitivo implicado na atividade matemática e às dificuldades de tal aprendizagem. Atualmente, é professor emérito na Universidade Du Littoral Côte d'Opale da França. No Brasil, tem contribuído com os estudos na área da educação matemática, sobre a aprendizagem matemática e as representações semióticas, por meio de suas publicações e de encontros com estudantes e pesquisadores.

A obra em francês Sémiosis et pensée humaine: registres sémiotiques et apprentissages intellectuels (1995) é um marco na teoria dos registros de representação semiótica e tem influenciado fortemente as pesquisas educacionais brasileiras. Por isso, recentemente, foi publicado o primeiro fascículo da tradução em língua portuguesa, a qual contém a introdução e o primeiro capítulo, cujo objetivo, segundo o próprio autor, é apresentar o quadro teórico global de que trata a obra original.

$\mathrm{Na}$ introdução, Duval antecipa o caráter central das representações semióticas em suas pesquisas, destacando a aprendizagem das matemáticas como um campo privilegiado de estudos sobre as atividades cognitivas fundamentais como a conceitualização, o raciocínio, a resolução de problemas e a compreensão de textos. Diante disso, ele enfatiza que as atividades cognitivas relacionadas à aprendizagem da matemática estão ligadas ao uso de sistemas de expressão e representação como a língua natural, os sistemas de escrita de números, as escritas algébricas, as notações simbólicas formais, as figuras geométricas planas ou em perspectiva, os gráficos cartesianos, os diagramas etc. $\mathrm{O}$ autor defende que as representações mentais não podem ser consideradas independentes das representações semióti-

http://dx.doi.org/10.5335/rep.2013.3518

Graduada em Matemática - Licenciatura Plena, pela Universidade de Passo Fundo (UPF), mestranda em Educação pela UPF e coordenadora do ensino fundamental da Escola St. Patrick, em Passo Fundo. E-mail: flavia.niemann@ terra.com.br 
cas, pois não há noésis sem semiósis; ou seja, a apreensão conceitual de um objeto matemático depende da produção e coordenação de diferentes representações semióticas.

O primeiro capítulo, intitulado "Registros de representação, compreensão e aprendizagem", é composto por um texto introdutório e cinco seções. No texto introdutório, Duval lança mão de pressupostos teóricos de estudiosos como Piaget, Vygotsky, Schoenfeld e Pierce para apresentar um panorama geral das concepções de representação, representação mental e representação semiótica, as quais influenciaram os estudos na área da psicologia cognitiva. Com isso, explicita, claramente, as três atividades cognitivas inerentes a toda representação que os sistemas semióticos devem permitir. A primeira está relacionada à constituição de traços perceptíveis que possam ser identificados, em um sistema determinado, como a representação de alguma coisa. A segunda refere-se à possibilidade de se transformar as representações por meio de regras próprias ao sistema, a fim de se obter outras representações que constituam uma relação de conhecimento possível de se comparar com as representações iniciais. Por fim, a terceira atividade integra a conversão de representações produzidas em um determinado sistema em representações de um outro sistema, de forma que estas permitam informar outros significados do que está sendo representado.

Na primeira seção, "Representações semióticas e aprendizagem", o autor explora as relações existentes entre representações mentais, computacionais e semióticas e classifica os diferentes tipos de representações. Nesse sentido, ele destaca que a diversidade dos sistemas semióticos tem papel fundamental para a aprendizagem matemática, pois as representações semióticas permitem uma variedade de representações referente a um mesmo objeto. Além disso, Duval destaca que todo progresso qualitativo na aprendizagem passa pela aquisição de tratamentos quase instantâneos que dependem dos tratamentos intencionais.

Em "As atividades cognitivas fundamentais de representação ligadas à semiósis”, o autor descreve as atividades cognitivas inerentes à semiósis: a formação de representações num registro semiótico particular e a transformação de uma representação em outras que conservam todo o conteúdo da representação de partida ou uma parte dele. Salienta-se que há dois tipos diferentes de transformações de registros de representação, o tratamento e a conversão. O tratamento é a transformação de uma representação em outra no mesmo registro, ou seja, uma transformação interna a um registro de representação ou a um sistema semiótico, e a conversão refere-se às operações em que o registro de partida é transformado em outro registro de sistema semiótico diferente, isto é, uma transformação externa em relação ao registro de representação de partida. Nessa perspectiva, ele apresenta, também, 
os atos mais elementares de formação de representações semióticas e as regras de conformidade, que são aquelas que definem um sistema de representação, concluindo a seção de modo a evidenciar o papel indispensável da conversão para que o sujeito perceba a diferença entre o conteúdo de uma representação e aquilo que ela representa, favorecendo, assim, a coordenação dos registros de representação.

A seção "Problemas específicos às mudanças de registro" levanta a discussão diante das dificuldades da atividade cognitiva de conversão, focando os problemas de congruência e não congruência na mudança de registros. $\mathrm{O}$ alerta dado pelo autor refere-se à determinação da congruência entre duas representações, lembrando que, para verificar se duas representações são congruentes, é preciso segmentá-las em unidades significantes respectivas, de tal maneira que possam ser colocadas em correspondência. Dessa forma, os três critérios de congruência são: a correspondência semântica entre unidades significantes, univocidade semântica terminal e mesma ordem passível de apreensão dessas unidades nas duas representações.

Para ilustrar os entraves de conversão de registro, Duval apresenta os resultados da pesquisa de Vergnaud e Damm (1992) sobre as mudanças de registros usados na resolução de problemas aditivos registrados em língua natural para a escrita da equação aritmética e as dificuldades apresentadas diante da não congruência dos registros. As pesquisas realizadas pelo autor, em 1971 e 1988, também revelam a dificuldade dos alunos ao realizarem a conversão de registros não congruentes, constatando um fechamento dos registros de representação e a impossibilidade de coordenar diferentes registros, condição indispensável para a compreensão.

$\mathrm{Na}$ quarta seção, "Estrutura multirregistro da representação e atividade conceitual”, destacam-se a importância da diversificação dos registros de representação semiótica no ensino da matemática e a implicação da coordenação dos registros de representação na atividade conceitual; ou seja, a compreensão conceitual aparece ligada à descoberta de invariantes entre representações semióticas heterogêneas. Para isso, o autor apresenta o modelo linguístico da representação centrado sobre a função de expressão, o modelo operatório centrado sobre a função de tratamento e, por fim, o modelo cognitivo da representação centrado sobre a função de objetivação. Nessa seção, também, fica explícito um dos pressupostos centrais da teoria dos registros de representação sobre a necessidade de não confundir o objeto matemático com a sua representação, razão pela qual é imprescindível coordenar diferentes representações semióticas referentes a esse objeto.

$\mathrm{Na}$ última seção do capítulo, "As condições de uma aprendizagem fundada sobre a coordenação dos registros”, são externados os conceitos de compreensão monorregistro (aquela adquirida diante de um só registro, ou que privilegiou um registro particular) e a compreensão integrativa (fundada na coordenação de di- 
ferentes registros, estando a aprendizagem centrada na conversão de representações). Duval esclarece que as situações de aprendizagem focadas na coordenação de registros requerem a identificação de todas as variações de uma representação num registro, prevendo e observando as variações simultâneas de representações em outro registro. Nessa perspectiva, a língua, como ponto de partida a toda a aprendizagem relacionada a um ensino, tem papel fundamental para a realização de variações sistemáticas entre a conversão das representações não discursivas e das expressões em língua natural.

Para os pesquisadores e educadores matemáticos, a leitura do primeiro fascículo da obra original, Semiósis e pensamento humano: registros semióticos e aprendizagens intelectuais, é uma excelente oportunidade de desafiar-se intelectualmente e conhecer os principais pressupostos que fundamentam a teoria dos registros de representações semióticas. Assim, a abordagem diante das transformações de registros de representação (conversões e tratamentos), que demonstram diferentes aspectos relacionados a um mesmo conceito matemático, pode se constituir em uma possibilidade de desvendar as dificuldades de aprendizagem dos estudantes na área da matemática.

\section{Nota}

1 Resenha da obra DUVAL, Raymond. Semiósis e pensamento humano: registros semióticos e aprendizagens intelectuais (fascículo I). Trad. de Lênio Fernandes Levy e Marisa Rosâni Abreu da Silveira. São Paulo: Livraria da Física, 2009. 